\title{
電磁血流計による頭蓋内単一脳動脈血流測定とその応用
}

\author{
島健・西田 正博*. 岡田 芳和*.魚住 徹*・西村 茂**
}

\section{Cerebral Arterial Blood Flow Measured with an Electromagnetic Flow Meter during Surgery}

\author{
Takeshi Shima, Masahiro Nishida*, Yoshikazu OKadA*, Tohru UozUmi* \\ and Shigeru NISHIMURA** \\ Department of Neurosurgery, Chugoku Rosai Hospital, Kure; *Department of Neurosurgery, Hiroshima \\ University, Hiroshima; **Department of Neurosurgery, Kitakyushu Yukawa Hospital, Kitakyushu
}

\begin{abstract}
Intracranial cerebral arterial blood flow was measured in 33 patients with an electromagnetic flow meter to investigate the hemodynamic state during surgery for cerebrovascular disease. These cases were composed of 25 intracranial aneurysms, 1 arteriovenous malformation, 1 hemangioblastoma, and 6 STA-MCA anastomosis. Specially designed probes were made and an electromagnetic flow meter with the auto-zero balance system was used to facilitate measurement of the cerebral arterial blood flow. A probe with an appropriate size and sensitivity was applied to the carefully exposed cerebral artery. Blood flow could be measured in the internal carotid artery (ICA) (14 cases), $\mathrm{M}_{1}$ ( 7 cases) and $\mathrm{M}_{2}$ portion ( 3 cases) of the middle cerebral artery (MCA) and in the surperficial temporal artery (STA) after bypass surgery. The collateral potential of the circle of Willis was evaluated from the changes in MCA blood flow following test occlusion of the ICA in 2 cases. The effects of brain retraction ( 8 cases) and induced hypotension with ATP infusion method ( 8 cases) were also studied.

The mean arterial blood flow in the ICA, $\mathrm{M}_{1}$ and $\mathrm{M}_{2}$ portion of the MCA were $144 \mathrm{~m} / / \mathrm{min}, 81 \mathrm{~m} / / \mathrm{min}$, and $28 \mathrm{~m} / / \mathrm{min}$, respectively. The anastomotic blood flow in the STA was $27 \mathrm{~m} / / \mathrm{min}$ on the average. Test occlusion of the ICA demonstrated the patient's collateral capacity through the anterior and posterior communicating arteries in each case. Induced hypotension showed that the arterial blood pressure threshold of the autoregulatory response was $58 \mathrm{mmHg}$ in normotensive patients. Brain retraction, ranging from 150 to $300 \mathrm{mmH}_{2} \mathrm{O}$ (average $250 \mathrm{mmH}{ }_{2} \mathrm{O}$ ), decreased blood flow by approximately 20 percent of the control value.

It was suggested that the specially designed probes and electromagnetic flow meter could investigate the intracranial arterial blood flow during surgery without any serious side effects. Measurements of the cerebral arterial blood flow with this method gave important clues to the management of the main cerebral arteries and to the protection of the brain from ischemic insult.
\end{abstract}

Key words: electromagnetic flow meter, cerebral aneurysm, induced hypotension, cerebral blood flow, collateral circulation

\section{I はじめに}

腷血流測定には，最近では ${ }^{133} \mathrm{Xe}$ 内頸動脈泩入法による 大脙半球の局所脳血流测定法加ら，侵襲の少ない ${ }^{133} \mathrm{Xe}$ 吸 入法が普及しつつある。一方，非侵襲的な超音波 Doppler
法による脳血管障害患者の血流動態の検索も進的られてい る。これに対し，もっとも定量的な血流測定方法として古 くから知られている電磁血流計忹，血管を露出しなければ ならないという久点があるため，頸部手術症例での頸部脳 動脈への応用に限られていた。しかし近年, 電磁血流計に

中国労苂病院媨神経外科 *広島大学腷神経外科 **北九州湯川総合病院媨神経外科

Address reprint requests to: T. Shima, M. D., Department of Neurosurgery, Chugoku Rosai Hospital, 1, 477 Hiromachi, Kure $737-01$.

受稿 1983年 1 月 10 日 受理 1983年 4 月 8 日 
はデジタル化，血流ぜロレベルの自動化，および安定性の 向上などの改良が加えられ，その操作もきわわて容易にな ってきている

我々は，この電磁血流計のプローブにさらに改良を加 え，脳深部脳動脈に装着できるようにした，本論文では， 主として脳動挀瘤手術時での電磁血流計による単一脳動脈 の血流測定により血流動態を梌索したので, 若干の考察を 加えたい.

\section{II 対象および方法}

対象注，1973年11月から1980年4月までの問に，広島大 学脳神経外科斿よび関連病院で手術を行った脳動脈瘤25 例, 脳動静脈奇形・ hemangioblastoma 各 1 例, 括上び STA -MCA 吻合術を行った 6 例の計33例である。

脳動脈瘤症例法いずれも夕モ膜下出血で発症し，手術時 の grade は Hunt \& Kosnik の分類で Grade I 18 例, Grade II 5 例, Grade III 2 例である，25例以外に 7 例で血流測定 を試みたが，強い動脈硬化や脳腫脹のため中止した，脳動 脈溜は，GOF 麻酔で全例手術顕微鏡下に pterional approach で neck clipping を行った。な拉前交通動脈瘤は， dominant な前大脳動脈 $\left(\mathrm{A}_{1}\right)$ を有している側加ら approach し，術中動脈癌の破裂が予想された症例で法，ATP(500 $\mathrm{mg} / 500 \mathrm{ml}$, アデホスコーワ() 点滴静注法による induced hypotension 利用した ${ }^{11)}$.

血流計は，自動ゼロレベル補正回路を内蔵した電磁血流 計 model MF-27 (日本光電) を用いだ,12)。プローブは, Fig. 1 亿示すような頭蓋内脳動脈流着しやすいように我 タが形状を改良した $1 ， 1.25 ， 1.5 ， 2.0 ， 2.5 ， 3.0 ３ .5$ $\phi$ の径で流量に適合した感度を有するものを用いた ${ }^{122}$. 脳 深部血流測定には, プローブを装着するのに視野が狭いこ
とや，装着する内頸動脈，中大脳動脈および前大脑動脈の いずれからも分枝している穿通枝の損傷が重要な問題点で ある。したがってプローブ作製にあたっては，プローブ本 体が視野の妨げにならない程度の大きさで，直接血管に装 着する部分の幅はできるだけ狭く，しかも血管への装着や 離脱が容易に行えるよらに開口部(slit) t大きるする，など の注意を払った。さらに，中大脳動脈起始 部 $\left(\mathrm{M}_{1}\right.$ 部)，前 大脳動脈の $A_{1}$ 部は，術野では手前に上がってきたり横走 するような位置となるため，プローブを血管へ装着する部 分ぶ手術顕微鏡下で十分確認できるようにプローブ本体に 10 20の角度をつけた，Fig. 2 は，3 3 のプローブを内 頸動脈に装着した状態を示している。血流測定は，穿通枝 の出ている場所ではできるだけ行わないように，たとえば 内頸動脈では後交通動脈上前脈絡動脈分枝部の間にプローブを装着した，プローブ装着後は，機械的刺激に上る攣縮 の予防招よびプローブと血管との適合をよくする目的で， 10倍希勫した塩酸パパベリンの局所塗布を行った，血流波 形は，カニューレーションによる動脈血圧とともにポリグ ラフ上に同時記録した，血流の変化を検索する目的での temporary occlusion は，マイクロピンセットで血管を一時 遮断したＳSTA-MCA 吻合術例では，浅側頭動脈の前頭 枝または頭頂枝にカニューレーション在行い，血玉測定を 行った，浅侧頭動脈の本幹部に $1.5 \sim 2.0 \phi て ゙ 50 \mathrm{~m} l / \mathrm{min} の$ 感度のプローブを装着して血流測定を行い, 全身動脈血 压，浅側頭動脈血圧，吻合部血流量の同時記録老行った。 さらに一部の症例では, 脳ベラによる脳圧迫の腷血流に及 ぼす影響を検索する目的で，脳べラと脳表の間に Ladd 社 製の頭蓋内圧測定用センサーを挿入し，retraction pressure の測定と同時に脳血流量を記録した。

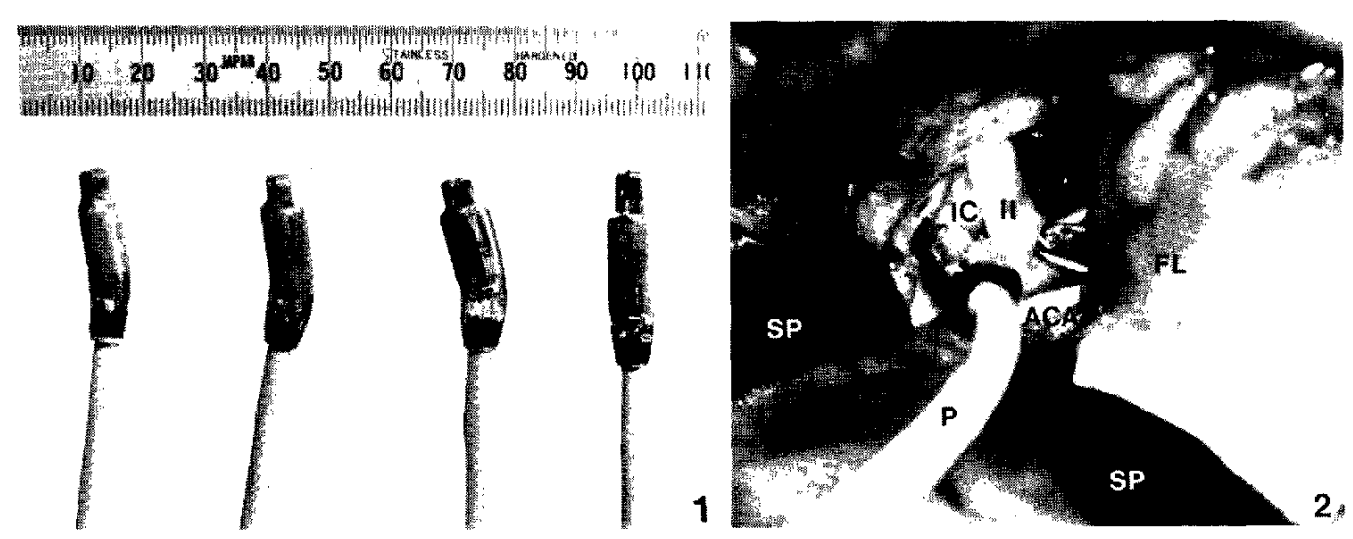

Fig. 1 Specially designed electromagnetic flow probes, with diameter 1.25, 2.0, 2.5, $3.0 \mathrm{~mm}$, respectively, from the left.

Fig. 2 Operative field shows a probc applied to the internal carotid artery (IC). ACA indicates anterior cerebral artery; SP, spatula; FL, frontal lobe; II, optic nerve. 


\section{III 結 果}

\section{1. 頭蓋内単一脳動脈の平均血流量}

内頸動脈血流はTable 1 のごとく，14例で19回の測定を 行い, $100 \sim 240 \mathrm{~m} l / \mathrm{min}$, 平均 $144 \mathrm{ml} / \mathrm{min}$ を示した. 血流 測定時の平均動脈血圧は $98 \mathrm{mmHg}$ であった，Fig. 3A は， 内莖動脈血流の代表的血流波形を示しておう，鋭いsystolic notch とそれと引き続く diastolic notch が明瞭である。 方, 中大脳動脈本幹部で調 ゙゙た 7 例の血流量は, $50 \sim 100$ $\mathrm{m} l / \mathrm{min}$, 平均 $81 \mathrm{~m} l / \mathrm{min}$ 在示 , 血流測定時の平均動脈 压は94 mmHgであった。Fig. 3B は代表的な中大脳動脈血 流波形であるが，内颖動脈血流波形に比して systolic notch は鋭さが減じている。3 例で測定した中大脑動脈分枝部 $\left(\mathrm{M}_{2}\right.$ 部) の平均血流量は, $28 \mathrm{ml} / \mathrm{min}$ で $\mathrm{M}_{1}$ 部の 約1/3で 西った(Fig. $3 \mathrm{C})$, 中大脳動脈領域の脳表動脈での血 流走 $1.0 \phi, 20 \mathrm{ml} / \mathrm{min}$ の感度のプローブを用いて3例で测定 した。 その平均血流量法 $8 \mathrm{~m} l / \mathrm{min}$ であった。

一方，4 例で測定した前大脎動脈 $\mathrm{A}_{1}$ 部の血流量は平均 $52 \mathrm{ml} / \mathrm{min}$ で, 血流測定時の動脈血圧注平均 $96 \mathrm{mmHg}$ で 㐫った。これららち, hypoplastic な $A_{1}$ 部で測定した血 流量注 $30 \mathrm{~m} l / \mathrm{min}$ と低值であった。

STA-MCA 吻合術後浅側頭動脈本幹部で測定した bypass flow の平均值汢 $27.1 \mathrm{~m} / / \mathrm{min}$ で, 血流測定時の平均 動脈血压は100 mmHg であった(Fig. 4)。

\section{2. 頭蓋内脸動脈一時遮断による内頚動脈血流の変化}

$A_{1}$ 部や $M_{1}$ 部の temporary clipping による内頸動服血 流の変化を，9症例10回の測定で検討した. Fig. 5A 洁 $\mathrm{A}_{1}$ 部を一時遮断したときの同側内頸動脈血流の変化を示して いるが，迅速な血流減少が明らかである。内頸動脈血流は， $133 \pm 40($ mean $\pm \mathrm{SD}) \mathrm{ml} / \mathrm{min}$ 加 $5 \mathrm{~A}_{1}$ clipping により平 均 $41 \pm 20 \mathrm{ml} / \mathrm{min}(32 \pm 13 \%)$ の減少をきたし, 平均 $92 \pm$ $38 \mathrm{~m} l / \mathrm{min}$ となった. 乙か し, 血流減少量は $20 \sim 85 \mathrm{ml}$ min，減少率では12.5 50\%と症例に上りかなりの差がみ られた。 2 例を除くと，いずれも dominant $A_{1}$ 在して いる側の内頸動脈血流を測定していることから，かなりの
Table 1 Blood flow values in the main cerebral arteries measured with an electromagnetic flow meter

\begin{tabular}{lrccc}
\hline $\begin{array}{l}\text { Applied site } \\
\text { of probe }\end{array}$ & $\begin{array}{l}\text { No. of } \\
\text { cases }\end{array}$ & $\begin{array}{c}\text { No. of } \\
\text { measurements }\end{array}$ & $\begin{array}{c}\text { Blood flow } \\
(\mathrm{m} l / \mathrm{min})\end{array}$ & $\begin{array}{c}\text { MABP } \\
(\mathrm{mmHg})\end{array}$ \\
\hline ICA & 14 & 19 & $144.3 \pm 39.0$ & $98.6+15.0$ \\
MCA $\left(\mathrm{M}_{1}\right)$ & 7 & 9 & $81.1=19.8$ & $94.0 \pm 16.8$ \\
MCA $\left(\mathbf{M}_{2}\right)$ & 3 & 4 & $27.7 \pm 10.0$ & $94.5+6.4$ \\
MCA $\left(\mathrm{M}_{2}\right)^{*}$ & 1 & 1 & 80.0 & 98.0 \\
MCA $\left(\mathbf{M}_{4}\right)$ & 3 & 3 & $8.0 \pm 0.5$ & $105.0 \pm 7.1$ \\
ACA $\left(\mathrm{A}_{1}\right)$ & 4 & 5 & $52.0 \pm 14.4$ & $96.0 \pm 16.7$ \\
PICA & 1 & 1 & 12.5 & 106.0 \\
STA** & 6 & 6 & $27.1=2.2$ & $100.0 \pm 11.0$
\end{tabular}

MABP indicates mean artcrial blood pressure; ICA, internal carotid artery; ACA, anterior cerebral artery; MCA, middle ccrcbral artery; PICA, posterior inferior cerebral artcry; STA, superficial temporal artery; * feeder of the artcriovenous malformation, ** STA-MCA anastomosis.

減少をきたしたものと考えられる。さらに，中大脳動脈領 城の vascular bed の大きさや, 脳べラの retract の影響も 考虑に入れる必要があるら。一方， $\mathrm{M}_{1}$ 部の一時遮断に上 る同側内頸動脈血流の変化を 7 例で検討した， $\mathbf{M}_{1}$ 部遮断 後の血流量は平均 $73 \pm 30 \mathrm{ml} / \mathrm{min}$ であり, $42 \pm 18 \%$ の減 少率考示した。立た，的管写上 anterior cross circulation の比較的良好な 2 例で中大脳動脈 ( $\mathbf{M}_{1}$ 部)の血流を測 定 し，同側内莖動脈の一時遮断の影響を検討した。 Fig. $5 \mathrm{~B}$ にとの 1 例を示すが，遮断により血流量が $82.5 \mathrm{~m} / / \mathrm{min}$ 加 ら $56.5 \mathrm{ml} / \mathrm{min}$ に約 $30 \%$ 娍少し, 遮断解除後の血流法明ら かな増加を示した，これらのことより，内頸動脈や中大脸 動脈血流を測定しながら他の主幹動脈を一時遮断すること により， collatcral circulationの良否を判断できることが 示唆された.

\section{3. 脳ベラによる脳 retraction の脳血流への影響}

$1 \cdot 2$ で述べた内頚動脈，前大腷動脈，中大脑動脈の血 流量は,いずれも脳ベラで媨を retractした状態下で測定し

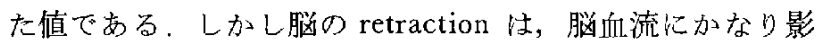
響を及ぼしているものと考えられる。そこで脳動脈にプロ

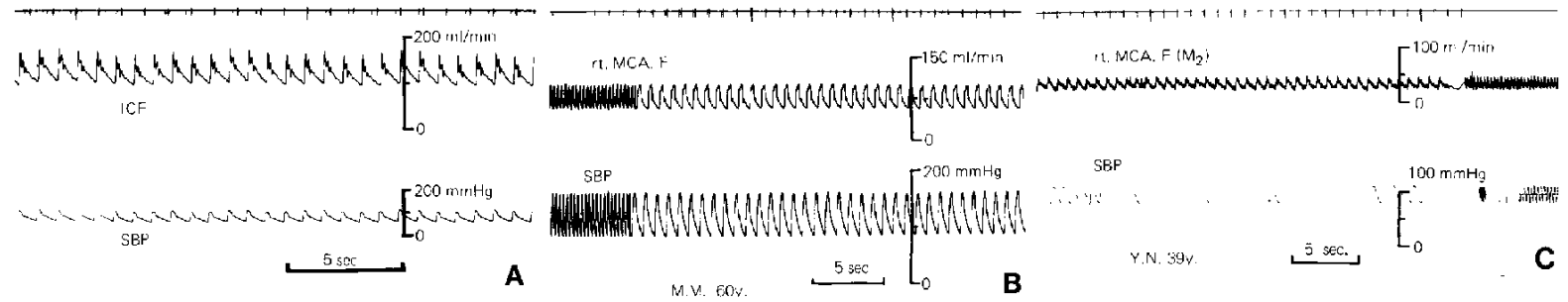

Fig. 3 Typical pulsatile blood flow patterns rccorded from the internal carotid artery (ICF) (A), $\mathbf{M}_{1}$ (B) and $\mathbf{M}_{2}$ (C) portion of the middle cerebral artery (MCA. F). SBP indicates systemic blood pressurc. 

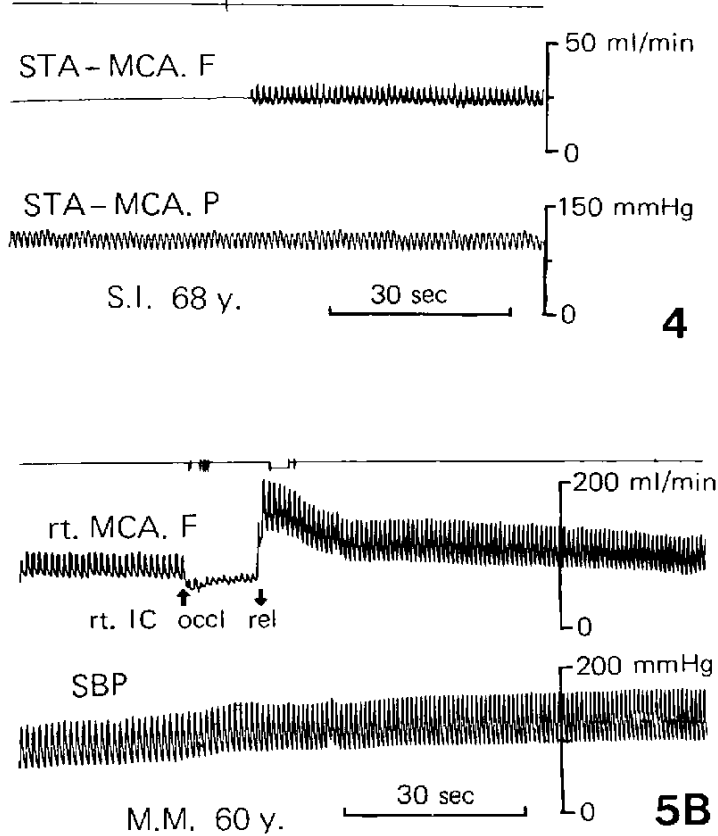

$30 \mathrm{sec}$

M.M. $60 \mathrm{y}$
5B
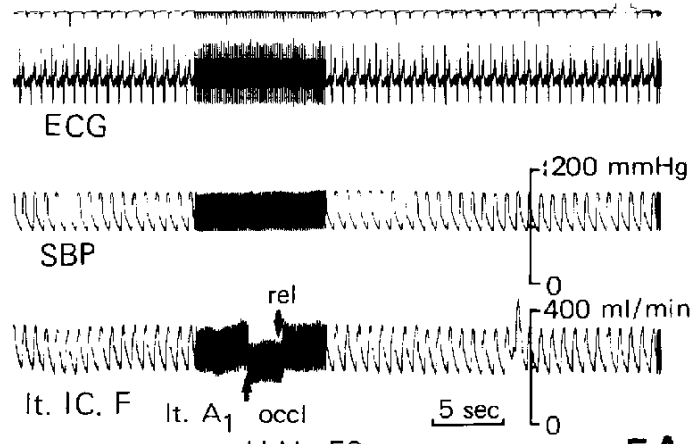

H.U. 59 y.

$5 A$

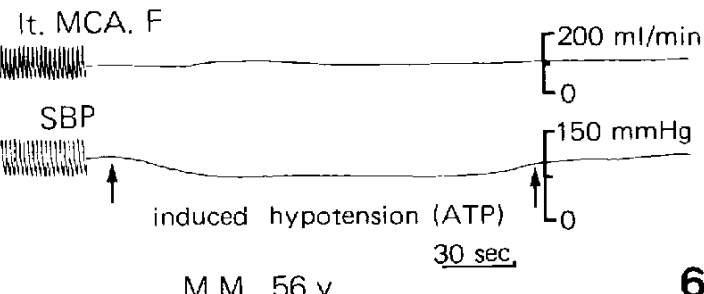

Fig. 4 Anastomotic blood flow (STA-MCA.F) and side pressure (STA-MCA.P) recorded from the superficial temporal artery after STA-MCA anastomosis.

Fig. 5 A: Temporary occlusion of the $A_{1}$ portion produces a significant decrease in the unilateral internal carotid flow (IC.F) B: Effects of temporary occlusion of the internal carotid artery (IC) on the middle cerebral artery flow (MCA.F) occl indicates occlusion; rel, release.

Fig. 6 Induced hypotension produces insignificant changes in the middle cercbral artery flow (MCA.F). Period of infusion of ATP indicated by arrows. Pulseless portion of the graph indicates averaged values. SBP indicates systemic blood pressure.

ーブを装着しを状態で，脳ベラによる脳圧迫の脳動脈血流 への影響を操作後10分以内の変化で検討した．8例に打け る10回の測定では, retraction pressure は平均 253土54 $\mathrm{mmH}_{2} \mathrm{O}\left(150 \sim 300 \mathrm{mmH}_{2} \mathrm{O}\right)$ で, 血流法平均 $21 \pm 8.8 \%$ 減 少した.このらち内頸動脈で測定した 5 例では, 平均 $16 \pm$ $4.8 \%$ 血流減少し加認机な⿰力口たのに対し，中大脳 動脈で測定した 3 例では，平均 $30 \pm 6.1 \%$ の減少が認めら れた。しかし retraction pressure の程度と血流減少度につ いては，症例も少なく細かい検討はできなかった。

\section{ATP点滴静注法による induced hypotension の脳動 脈血流に及ほす影響}

内頸動脈 ( 7 例) や中大脳動脈（1 例) で，血流を測定しな がらATP 点滴静注法により平均動脈血压を約 $30 \sim 40 \%$ 下 げ，autoregulatory response を調べた．Fig. 6 にその1例 を示す。平均動脈血圧は約 110 加ら $70 \mathrm{mmHg}$ に低下して いるが血流柱ほぼ一定であり，十分な autoregulatory response を示している。術前正常血圧の範囲にあった6 例 では，平均動脈血圧が58 mmHg で autoregulatory response の消失がみられたが，術前高血圧症を有していた 2
例では, $85 \mathrm{mmHg}$ が autoregulatory response の下限であっ た。な招症例はいずれも脳動脈瘤症例で，grade であった

\section{5. 合併症}

術後の死亡例はなく，2例で血管操作によると考えられ る一過性の不全麻放を認为たが，いずれも軽快した。

\section{IV 考察}

臨床例で最初に頭蓋内单一脳動脈血流を定量的に測定し たのは Nornes で，内頸動脈海綿静脈洞瘦症例での頭蓋内 内頸動脈血流を電磁血流計で測定したものである5 報告後, 彼はさらに脳動脈瘤の手術時にも脳主幹動脈の血 流測定を行い，血流動熊の検索をしている 彼の使用した電磁血流計 (Nycotron，Licr，Norway) が血流 ゼロレベルの自動化機構を内蔵していないため，血流量を 定量的に知るためには，そのつどプローブを装着した血管 の遠位部を一㭙的に遮断してゼロレベルを決める必要があ った。この脳動脈遮断は一時的で法あるが煩雑であり，し かも危険を伴うものである，加えて，頭蓋底部の単一血管 
の血流を電磁血流計で測定する場合，広い視野が得られな い，重要な穿通枝が存在する，血管内膜を損傷するおそれ がある，機械的血管摮縮索発生させる可能性がある，など の問題がある。したがって，これまでの電磁血流計による 㨫血流測定注主として研究室レベルで行われてきた 一方，我々が用いた日本光電で開発された電磁血流計 MF -27型, 拈よび最近さらに小型化された MFV-100型, MFV-1200型は，血管考直接・機械的に閉塞することなく 血流ゼロレベル(non-occlusive zero) を求めるこ上ができる ゼロ安定化回路が採用されている 以下，デフィブリレーター保護回路内葴など，きわわて高 い電気的安定性を有している，プローブは，頭蓋内媣部の 脳主幹動脈に装着するため，抢のおのの血管径に良く適合 した小型で高感度なものでなくてはならない，我々は，日 本光電の協力のもとに種々の大きさのプローブを作製 し た ${ }^{122}$.この結果, 内頸動脈血流測定用には3.5 2.5 $\phi$, 中

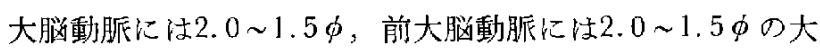
きさで，プローブ本体に曲がりをつけたものが使いやすか った.

本研究での頭蓋内各主要血管の平均血流量は, 内頸動脈 で $144 \mathrm{~m} / / \mathrm{min}$, 中大脳動脈で $81 \mathrm{ml} / \mathrm{min}$, 前大脳動脈で 52 $\mathrm{m} l / \mathrm{min}$ であった。これらの值はいずれす，Nornes らが 報告している内頸動脈血流量 $144 \mathrm{~m} l / \mathrm{min}$ ，中大脳動脈血流 量 $97 \mathrm{ml} / \mathrm{min}$, 前大腷動脈血流量 $65 \mathrm{ml} / \mathrm{min}$ 上良く一致 L ていだ．しかし内頸動脈や前大脳動脈血流量に関して は，同側の前大脳動脈の発達の程度によりかなり異なって くる可能性が大きく，今後さらに詳細な検討が必要と考え られる。

脳外科的疾患，たとえば内頸動脈海綿静 脈洞瘦 (CCF), 内䫫㧍上び中大腷動脈領域の巨大動脈瘤, 内钼動脈を involve している脑腫瘍などの外科的治療に際して，一側 の内頸動脈を遮断せざるをえない場合がある。このような 場合, 術中電磁血流計を用いて中大脳動脈血流を定量的に 測定寸れば，内頸動脈遮断時の cross circulation の良否を 含めた血流動態が把握でき, 治療方針を決定するのに好都 合である、Nornes ${ }^{5}$ らは，CCF 患者で瘦に流れ込む血流 量加ら内頸動脈の trapping の安全性の是非を決めている.

一方，脳動静脈奇形などの異常な血流動態の検菜におい ても，本法による脳動脈血流の測定は有用である。たと京 ば，中大脳動脈分枝部 $\left(\mathrm{M}_{2}\right.$ 部) の血流量は平均 $28 \mathrm{~m} l / \mathrm{min}$ で，中大脳動脈本幹部 $\left(\mathrm{M}_{1}\right.$ 部)の約1/3であった。このよう な中大脳動脈領域の血流分配状態に対して, 脳動静脈奇形 の feeder となっていた中大脳動脈分枝部 $\left(\mathrm{M}_{2}\right.$ 部)におけ る血流量は約 $80 \mathrm{~m} / / \mathrm{min}$ であり， $\mathrm{M}_{1}$ 部に一致した血流量 が steal されていることが明らかにできた。
脳ベラによる遒の retraction は，脳動脈瘤などの手術に 際してもっとも重要な操作であるが，方の脱循環に対する 影響の臨床的研究はほ上んどない，本研究で脑べラによる retraction pressure と脳動脈血流量との関倸を検索したとこ 万, 平均 $250 \mathrm{mmH}_{2} \mathrm{O}$ の retraction pressure に上り血流量

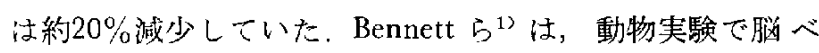
ラによる retraction pressure の脸機能に及ぼす影響を，体 性感覚誘発電位(SEP) 指標として検索している，その結 果, $30 \mathrm{mmHg}$ 以下の圧で 1 時閒 retract した場合 SEP は 26\%以内の低下にとどまり，40 50 mm tr では50\%の低 下をきたしている，さらに，induced hypotensionにより平 均動脈血压 $50 \mathrm{mmHg}$ まで低下させた状態では，10２0 $\mathrm{mmHg}$ の retraction pressure でも SEPは50\%以下になり， 脳組織に不可逆的な変化が生していることを明らかにし， SEP の記録が譄機能の良い指標になることを示唆してい る.

脳血流量とSEP などの脑機能の指標との関係は, 多く の動物実験や臨休例で報告されて招り，正常状態の脳血流 量の30 40\%が，明らかな脳機能障害を生じる critical level とされている ${ }^{2-4,9,10,16)}$. 以上の事実から考えると， 本研究での retraction pressure $200 \sim 250 \mathrm{mmH}_{2} \mathrm{O}$ による脳 動脈血流の約20\%の減少注，脳機能をほとんど変化させな いかもしれないと思われる。しかし，クモ膜下出血後で脳 循環障害が少なからず生じている患者などでは，脳の retractionの影響は正常脳を压迫するよりも著明な脳循環 障害を生じるとも推察でき，術中の脳べラによる脳の retraction はできるだけ軽度にとどめるとともに，本法庄 用いて retraction pressure 索術中検討してみることも重要 と考光られる。

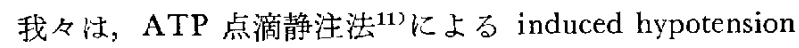
時の autoregulatory response を調べたが，大多数の症例で 動脈血圧が平均約 $60 \mathrm{mmHg}$ に低下寸るまで血流は一定に 維持されていた。 しかし術前高血厌症を有していた2例で は, autoregulatory response $の$ 下限法約 $85 \mathrm{mmHg}$ とやや上 昇していた ${ }^{15)}$. Nornes $ら^{7)}$ は, trimethaphan camsylate (Arfonard)による induced hypotension により autoregulatory response 在維持し, 脑動脈瘤症例で術前Grade I ・ II のものでは autoregulatory response の下限は動脈血圧約 $62 \mathrm{mmHg}$, Grade IIIでは76 mmHg と報告している。我ヶ の脳動脈瘤症例は注とんどが Grade I ・ II で, 動脈瘤破 裂後 2 週間以上経過して手術したものであることや， induced hypotension の方法が異なることから，gradeによる autoregulatory response の下限の比較検討はできなかった。

以上，脳動脈瘤手術時に扮汀る，電磁血流計に上る頭蓋 内単一脳動脈血流の測定方法の害際を中心述べた，本法 
は，正確加慎重な血管操作と血流計の取り报いを行之 ば，術中の血流動態が速やかに把挃でき，腷機能の検索上 ともに治療方針の決定，術後合併症の予防や脳血管障害の 病態の解明に有用なものと考えられた。

\section{$\mathrm{V}$ ま め}

1. 頭蓋内各血管血流測定用の電磁血流計の特殊 プロー ブを作製し，脳血管障害患者33例の手術時に，直接血流を 定量的に測定した。

2. 内頚動脈血流量は平均 $144 \mathrm{~m} l / \mathrm{min}$, 中大脎動脈 $\mathrm{M}_{1}$ 部 $81 \mathrm{~m} l / \mathrm{min}, \mathrm{M}_{2}$ 部 $28 \mathrm{~m} / / \mathrm{min}$, 前大脳動脈 $\mathrm{A}_{1}$ 部 $52 \mathrm{ml}$ / min であった。また，STA-MCA 吻合術後の血流量は 平均 $27.1 \mathrm{ml} / \mathrm{min}$ であった。

3. 譄べラ圧排により檤血流に及ぼされる影響を検索し たが，平均 $250 \mathrm{mmH}_{2} \mathrm{O}$ の圧で血流はおよそ $20 \%$ の減少を きたした。

4. Temporary clip による各血流の変化を調べたが, 血 流変化は迅速に起こり, cross circulation collateral capacity を知る上できわ好て有用で如った。

5. ATP 点滴静注法による人為的低血圧時の血流の変 化を検討した，術前正常血圧例では，全身血圧は平均 58 $\mathrm{mmHg}$ 上なり血流も低下したが，高血圧を有していた 2 例では, $85 \mathrm{mmHg}$ 上 autoregulatory response の下限の上 昇が認めら机た。

6. 本法は，Doppler 法とともに術中の血行動態を知る 上で有力な手段と考えられた。

プローブ作製にあたり全面的に御協力下さいむした日本光電工 業株式会社 小川桂屹氏に感謝の意を表します，また，血流測定に 好意的に御協力頂きました中国労災病院，双三中央病院，広島総 合病院各脳神経外科の諸先生方に厚く御礼申し上げます。

本論文の一部は第38回日本脳神経外科学会総会 (1979年10月, 東 京), 第22回脳循環代謝研究会 (1979年10月, 東京), 7 th International Congress of Neurological Surgcry(1981年 7 月, München) に扔いて発表した。

\section{文献}

1) Bennett MH, Albin MS, Bunegin L, Dujovny M, Hellstron H, Jannetta PJ : Evoked potential changes during brain retraction in dogs. Stroke 8: 487-492, 1977

2) Branston NM, Symon L, Crockard HA, Pastor E: Relationship between cortical evoked potential and local cortical blood flow following acute middle cerebral artery occlusion in the babboon. Exp Neurol 45: 195-208, 1974

3) Eisenberg HM, Turncr JW, Teasdale G, Rowan J, Fcinstein R, Grossman RG: Monitoring of cortical excitability during induced hypotension in ancurysm operations. $J$ Neurosurg 50: 595-602, 1979

4) Grossman RG, Turner JW, Miller JD, Rowman JD The relationship between cortical electrical activity, cerebral perfusion pressure and cerebral blood flow during increased intracranial pressure. Stroke 4: 346-347, 1973

5) Nornes H: Hcmodynamic aspects in the management of carotid-cavernous fistula. $J$ Neurosurg 37:687-694, 1972

6) Nornes H, Kuntzen HB: Cerebral arterial blood flow and aneurysm surgery. Part 1. Local arterial flow dynamics. I Neurosurg 47: 810-818, 1977

7) Nornes H, Kuntzen HB: Cerebral arterial blood flow and aneurysm surgery. Part 2. Induced hypotension and autoregulation capacity. $J$ Neurosurg 47: 819-827, 1977

8）小川桂屹：矩形波電磁血流計技術 解 説. Khaden Report $27: 6-12,1979$

9）岡田芳和，島 健，魚住 徹：Embolization 法によ る中大脳動脈閉塞の実験的研究 一局所脳血流と evoked potential $の$ 相関について一。脳々神 $32: 417-424 ， 1980$

10）阙田芳和，島 健，魚住 徹：SHR 両側総䫷動脈閉 塞抢上び血行再開の局所媨血流量 一皮質脑波に与える 影 響一. 脳神外科 $9: 687-695,1981$

11) 岡田芳和, 兽我部貴士, 井口孝彦, 竹吉 悟, 西本安子, 津野信輔, 新井達潤, 横田 晃：ATP 低血圧麻醉時の徝 罡代謝に関する実駼的研究，脈管学 $17: 867 ， 1977$

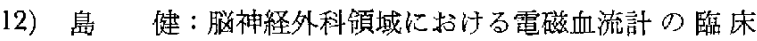
応用. Khoden Report $27: 1-5,1979$

13）島健，石川進，传々木潮：脳底動脈血流に関する 奏験的研究. 胀神外科 $4: 451-457 ， 1976$

14）島健, 石川 進, 佳々木潮, 宮崎正毅, 桑原 敏 電磁流量計による脳底動脈血流測定. 脈管学 14:251-254, 1974

15) Strandgard S, Olesen J, Skinh $\phi$ j E, Lassen NA: Autorcgulation of brain circulation in severe arterial hypertension. Brit Med J 1: 507-510, 1973

16) Teaskale G, Rowan JO, Turner J: Cerebral perfusion failure and cortical electrical activity, in Ingvar $\mathrm{DH}$, Lassen NA (eds): Cerebral Function, Metabolism and Circulation, Chapter 23. Copenhagen, Munksgaad, 1977, pp 14-15

〔別刷請求先： $\overline{7} 737-01$ 與市広町 1,477 , 中国労琰病院脳神 経外科，島 健 